\title{
DISPUTAS POR EL PRIORATO DEL HOSPITAL EN CASTIILA DURANTE LOS SIGLOS XIV Y XV *
}

\author{
por \\ CARLOS BARQUERO GOÑI
}

Universidad Autónoma de Madrid.

RESUMEN: Las disputas por el priorato del Hospital fueron muy frecuentes en Castilla durante la Baja Edad Media. Es estos conflictos intervinieron muy diferentes poderes, tales como la monarquia, la nobleza, el papa y el propio maestre del Hospital. En primer lugar, el rey pretendió controlar la designación de los priores del Hospital en la primera mitad del siglo XIV, pero finalmente fracasó. A continuación fueron los propios bospitalarios castellanos quienes lucharon entre si por el cargo. Finalmente, la monarquia consiguió imponer a sus candidatos en el priorato. Sin embargo, no se llegó a una incorporación formal a la corona, como ocurrió con los maestrazgos de las órdenes militares peninsulares. Por regla general, ele prios del Hospital era una persona procedente de la baja y mediana npbleza durante el siglo XIV. En cambio, el cargo empezó a ser ocupado por segundones de importantes linajes de la alta nobleza castellana a fiones del siglo $X V$.

PALABRAS CLAYE: Edad Media, Castilla, conflictividad, ordenes millitares, hospitales, monarquía, Iglesia, nobleza.

ABSTRACT: The struggles for the priory of St. Jobn were very frequent in Castile in the late Middle Ages. Many powers wanted to nominate candidates for this post: the Castilian monarchy, the nobility, the papacy and the master of Rhodes. The king unsucessfully tried to choose the priors in the first balf of the fourteenth century. Afterwards there were many quarrels amongst the Castilian Hospitallers for that office. Finally, the king managed to impose bis men in the priory. However, he did not manage to incorporate it formally to join it to the Crown, as be did with the masterships of the Spanish Military Orders. The prior of St. Jobn was usually a person from the lower aristocracy in the four-

* El presente trabajo ha sido realizado con la ayuda de una beca postdoctoral de la Fundación Caja de Madrid. Las principales siglas y abreviaturas utilizadas son las siguientes: AHN , OOMM= Archivo Histórico Nacional, Sección de Órdenes Militares.

AHN, Códices= Archivo Histórico Nacional, Sección de Códices.

AGP, Infante don Gabriel= Archivo General de Palacio, Sección Infante don Gabriel.

Hipania, LVIlI/2, núm. 199 (1998) 537-557 
teenth century. Conversely, the position began to be occupied by younger sons of important lineages of the bigh Castilian nobility.

KEY WORDS: Middle Ages, Castile, conflicts, military orders, Hospita. llers, monarchy, Church, nobility.

Los conflictos desatados entre la nobleza por la obtención de cargos de las órdenes militares peninsulares durante la Baja Edad Media son bien conocidos. Se trata de un tema que ya ha sido bastante bien estudiado desde hace tiempo, en especial por lo que se refiere a los maestrazgos de las órdenes. La violenta lucha por estos puestos, que constituían una buena fuente de rentas y de poder, sólo finalizó con la incorporación de los maestrazgos de las órdenes de Santiago, Calatrava y Alcántara a la Corona a fines del siglo XV ${ }^{1}$. Sin embargo, queda todavía por estudiar el caso especial de la Orden del Hospital o de San Juan. Se trataba de la única orden militar internacional que contaba con una presencia notable en Castilla durante los siglos XIV y XV, tras la disolución de la Orden del Temple. El centro de la Orden del Hospital en esta época se encontraba en la isla de Rodas, donde por regla general residía su maestre ${ }^{2}$. En Castilla lo que había era un prior, teóricamente subordinado a este maestre, que estaba a cargo de la administración de todas las posesiones hospitalarias presentes en el reino ${ }^{3}$. Además, harden de San Juan también cuenta con la particularidad de que no llegó a ser absorbida por la monarquía, a diferencia de las demás. Por tanto, nos ha parecido que setía interesante dedicar alguna atención al tema, ya que vamos a ver confluir en él los intereses de muy diferentes poderes y grupos sociales: la nobleza y la monarquía en Castilla, y el Papado y los hospitalarios de Rodas en el exterior. Las siguientes líneas pretenden ser tan sólo una primera aproximación general a una materia que probablemente requiera un estudio más completo y exhaustivo. Nos centraremos en los enfrentamientos surgidos en torno al nombramiento de la cabeza de los hospitalarios castellanos: el prior de San Juan.

1 CALDERON ORTEGA, José Manuel, «Pugnas nobiliatias pata el control de las dignidades de las órdenes militares en la Castilla bajomedieval: el caso de la encomienda de Azuaga (14651478)m: Espacio, Tiempo y Forma. Serie III, Historia Medieval 1 (1988) 97-135. LADERO QUESADA, Manuel Fernando, «La incorporación del maestrazgo de Alcántara a la Corona»: Hispania 150 (1982) 5-14. PORRAS ARBOLEDAS, Pedro Andrés, Los ser̃orios de la Orden de Santiago en su provincia de Castilla durante el siglo XV, vol. 1, Madrid 1982, págs. 30-56. SOLANO, Emma, La Orden de Calatrava en el siglo XV. Las señorios castellanos de la Orden al fin de la Edad Media, Sevilla 1978, pags. $57-125$.

2 Lu'riReLL, Anthony, "The Hospitallers at Rhodes, 1306-1421n: The Hospitallers in Cyprus, Rhodes, Greece and the West. 1291-1440, Londres 1978, item I, 278-313. ROSSI, Ettore, «The Hospitallers at Rhodes, 1421-1523»: en SETTON, Kenneth M. (Ed.), A History of the Crusades, vol. 3, Madison 1975, 314-339.

3 GuerRero VenTAS, Pedro, E/gran priorato de San Juan en el Campo de La Mantha, Toledo 1969 , págs. 97-110.

Hipastia, LVIIV/2, nủm. 199 (1998) 537-557 
Para hacerse una idea de la importancia relativa del asunto, puede ser interesante señalar que en el año 1505 se calcula que la renta del prior de San Juan era de 15.000 ducados, mientras que las de los maestrazgos de Santiago, Calatrava y Alcántara suponían 40.000,35.000 y 35.000 ducados, respectivamente ${ }^{4}$.

\section{EL NOMBRAMIENTO DE LOS PRIORES DEL HOSPITAL EN CASTILIA DURANTE LOS SIGLOS XII Y XIII}

Necesariamente, el punto de partida tiene que ser la situación existente en los siglos XII y XIII. El prior de la Orden del Hospital en los reinos de Castilla y León es una figura que aparece en el siglo XII. En concreto, la primera mención al cargo que hallamos es del año $1135^{5}$. Para el caso castellano carecemos de documentación específica sobre el procedimiento de designación del prior. Tan sólo se conserva un diploma de nombramiento por un cargo superior, el gran comendador del Hospital en España, de un lugarteniente suyo para el priorato de Castilla y León en el año $1269^{\circ}$. El elegido fue el comendador sanjuanista de Consuegra, frey Juan Núñez. Sin embargo, se trata sólo de la persona que se hace cargo de la administración del priorato de forma interina, mientras estaba vacante el puesto de prior: Por lo tanto, habremos de suponer que en Castilla se aplicaba la normativa general de la Orden de San Juan para todos los priores europeos. Al parecer, en un principio eran nombrados por el capítulo general de la Orden, pero a fines del siglo XIII el maestre empezó a controlar su designación ${ }^{7}$. Tampoco tenemos noticias concretas de disputas por el priorato de Castilla en la época. Tan sólo hay una confusa referencia que pudiera traslucir algún conflicto por este motivo. Se trata de una carta de los hospitalarios portugueses al maestre de la Orden, Guillermo de Villareto, del año 1298 en la que le responsabilizaban del mal estado del priorato de Castilla y León por haber nombrado dos priores en un corto espacio de tiempo ${ }^{8}$.

\section{INTENTOS DE LA MONARQUIA POR CONTROLAR LA DESIGNACIÓN DEL PRIOR DEL HOSPITAI EN LA PRIMERA MITAD DEL SIGLO XIV}

Los primeros conflictos documentados por el priorazgo de San Juan aparecen en Castilla durante el siglo XIV y fueron motivados por la pretensión regia

4 LADERO QUESADA, Miguel Angel, «Comentario sobre los señotios de las órdenes militares de Santiago y Calatrava en Castilla la Nueva y Extremadura a fines de la época medievaly: Las órdenes militares en el Mediterráneo Occidental. Siglos XIII-XVIII, Madrid 1989, pág. 180.

5 AYala MartíneZ, Carlos de (Compilador), Libro de privilegios de la Orden de San Juan de Jerusalén en Castilla y León (siglos XII-XV), Madrid 1995, pág. 181.

6 AHN, OOMM, carpeta $153, \mathrm{n}^{\circ} 1$.

7 RILEY-SMIT, Jonathan, The knights of St. Jobn in Jerusalem and Cyprus, c. 1050-1310, Londres 1967,360 .

8 BENAVtDes, Antonio, Memr ias de don Fernando IV de Castilla, vol. 2, Madrid 1860, págs. $170-171$

Hìpanta, LVIII/2, núm. 199 (1998) 537-557 
de escoger a la persona que debía desempeñar el cargo. El primero de ellos tuvo lugar en el año 1328 y su causa fue la tebelión del prior del Hospital, Fernán Rodriguez de Valbuena, contra el privado del rey Alfonso XI, Alvar Núnez de Osorio ? Los comendadores y freires de la Orden de San Juan reaccionaron entonces acudiendo a presencia del rey. El monarca les entregó unas cartas dirigidas al papa y al maestre de Rodas en las que relataba la rebelión del prior. Alfonso XI, además, les pedía que destituyeran a Fernán Rodríguez y nombraran prior a otro miembro de la Orden, Alvar Núñez de Sarria. En efecto, el papa y el maestre asi lo hicieron tras ver las cartas del rey de Castilla. Sin embargo, al final la rebelión triunfó y Fernán Rodriguez disfrutó del favor real. Entonces a su vez consiguió de Alfonso XI otras cartas para el papa y el maestre solicitando que le devolvieran el priorazgo. Ambas autoridades no pusieron ninguna objeción para ello. Tras recibir los escritos del pontífice y del maestre otorgándole el priorato, Fernán Rodríguez hizo apresar a Alvar Núñez de Sarria y a otros miembros de la Orden. Ejecutó a algunos de ellos y a otros los encarceló a perpetuidad. Atemorizados, ciertos hospitalarios huyeron del reino. Fernán Rodríguez siguió siendo prior hasta su muerte ${ }^{10}$.

Es probable que el resultado final de este episodio influyera en el hecho de que la Orden de San Juan se salvase de la primera gran oleada de intervencionismo regio sobre las órdenes militares, que ocurrió precisamente durante el reinado de Alfonso XI "'. Aparentemente, los hospitalarios no sufrieron ningún tipo de presión por parte de la monarquía cuando falleció el prior Fernán Rodríguez de Valbuena en 1333. Sabemos que ocupó su puesto de forma interina el comendador de Lora y de Setefilla, Ruy Pérez de Bolaños, como lugarteniente de prior, hasta que llegó el nuevo prior, Alfonso Ortiz Calderón. Se trataba de un hospitalario que había vivido hasta entonces en Rodas. Conocemos que obtuvo el priorazgo por concesión del maestre de la Orden ${ }^{12}$.

La monarquía tendrá más éxito por algún tiempo en la siguiente disputa por el priorato del Hospital, ocurrida en circunstancias muy especiales durante el reinado de Pedro I. Sin embargo, finalmente las pretensiones regias también fracasaron. Los orígenes del problema se remontan al año 1354, cuando el papa Inocencio VI rogó al maestre de la Orden, Pedro de Corneillán, que designara a Juan Fernández de Heredia para ocupar el priorato de Castilla, entonces vacante. El pontífice argumentaba que era la persona adecuada para lograr la efectiva incorporación de los antiguos bienes templarios en Castilla a la Or-

9 CATALÁN, Diego, «El buen prior Hernán Rodríguez (1328)»: Siete siglos de romancero (Historia y poesia), Madrid 1969, págs. 15-56. 428 y 450 .

CATALán, Diego, Gran Crónica de Affonso XI. Edición critica, vol. 11, Madrid 1977, págs.

11 Moxo, Salvador de, «Relaciones entre la Corona y las órdenes militares en el reinado de Alfonso XIs: VII Centenario del infante don Fernando de La Cerda, Madrid 1976, págs. 117-158.

12 ROSELL, Cayetano (Ed.), "Crónica de Alfonso XI»: Crónicas de los reyes de Castilla, vol. 11, Madrid 1953, 247 y 252.

Hispania, LVIII/2, núm. 199 (1998) 537-557 
den de San Juan ${ }^{13}$. Llegados a este punto, puede ser necesario recordar que tras la disolución de la Orden del Temple a comienzos del siglo XIV, sus posesiones en Castilla habían sido repartidas entre la Corona, la nobleza y las órdenes militares peninsulares, a pesar de que el papa Juan XXII había ordenado su incorporación a la Orden de San Juan en 1319 i4.

El candidato propuesto por Inocencio VI era, efectivamente, un hábil politico y hombre de confianza del papa. Pertenecía a una familia de la baja nobleza aragonesa y tenía el cargo de castellán de Amposta, es decir, el puesto equivalente al de prior del Hospital en Aragón. El problema era que también se trataba de un estrecho colaborador del rey de Aragón, Pedro IV ${ }^{15}$. El maestre del Hospital y el convento de Rodas, en efecto, finalmente hicieron provisión del priorato de Castilla y León en la persona de Juan Fernández de Heredia. Sin embargo, Pedro I no admitió este nombramiento. Escribió a Heredia prohibiéndole la entrada en su reino y amenazando con tratarle como a un enemigo en caso de que intentara pasar a Castilla. Tras enterarse de tal circunstancia, Inocencio VI reaccionó enviando varias cartas sobre el tema entre enero y agosto de 1356 . Unas fueron dirigidas al propio monarca castellano, rogándole que no impidiera a Heredia hacerse cargo de la administración del priorato. Otras las envió a diferentes personajes importantes del reino, pidiéndoles que influyeran en el rey para que aceptara a Juan Fetnández de Heredia como prior. También requirió la intervención con este fin del legado pontificio, Guillermo, cardenal de Santa María en Cosmedín, y del chantre de la Catedral de Santiago de Compostela, Gutierre Gómez ${ }^{16}$.

Es posible que todas estas gestiones tuvieran algún resultado positivo. Quizás se llegara a algún acuerdo tácito. El hecho es que Heredia no llegó a entrar en Castilla, pero a partir de diciembre de 1356 lo vemos administrar efectivamente los asuntos del priorato castellano desde Aviñón por medio de lugartenientes. Además, aparte de ser prior de Castilla, seguía siendo castellán de Amposta y además prior de San Gil, en el sur de Francia. Esta situación se prolongó así hasta julio de $1358{ }^{17}$. Según relata el cronista Pedro López de Ayala, en ese año Pedro I mandó a los freires de la Orden de San Juan que tuvieran

13 ZUNZUNEgui ARAMBURU, José, Bulas y cartas secretas de Inocencio VI (1352-1362), Roma 1970, págs. 63-64.

14 ESTEPA, Carlos, «La disolución de la Orden del Temple en Castilla y León5: Cuadernos de Historia. Anexos de la revista Hispania 6 (1975) 121-186. MAR'rínEZ DíEZ, Gonzalo, Los templanios en la Corona de Castilla, Burgos 1993, págs. 185-270. BARQUERO GONI, Carlos, «El conflicto por los bienes templatios en Castilla y la Orden de San Juann: En la España Medieval 16 (1993) 37-54. MARTÍNEZ DÍEZ, Gonzalo, «El proceso de disolución de los templarios; su repercusión en Castillav: Los monjes soldados. Los templarios y otras órdenes militares, Aguilar de Campoo 1996, 87-106.

15 Lu'TTRELl, Anthony, wJuan Fernández de Heredia at Avignon: 1351-1367w: The Hospitallers in Cyprus, Rbodes, Greece and the West, 1291-1440, Londres 1978, XIX, 289-316.

16 ZUNZUNEGUI ARAMBURU, José, Bul.s y cartas secretas de Inocencio VI (1352-1362), Roma 1970, págs. 204-205, 209-212, 219, 225-226, 230-231, 253-254.

17 AHN, Códices, $602-\mathrm{B}$, folios 140 recto- 164 vuelto.

Hispania, LVIII/2, vúm 199 (1998) 537.557 
por prior a Gutier Gómez de Toledo y así se hizo ${ }^{18}$. Al parecer, la medida está relacionada con la invasión de Castilla por Enrique de Trastamara a fines de junio de 1358. Gutier Gómez era un hombre de confianza del rey. Con anterioridad había sido freire de la Orden de Alcántara y comendador de Montalbán en la Orden de Santiago. Inmediatamente después de convertirse en prior de San Juan, prestó importantes servicios armados a Pedro I ${ }^{19}$. En cuanto al origen social de Gutier Gómez de Toledo, sabemos que pertenecía a una familia de la nobleza urbana de Toledo ${ }^{20}$.

Una carta dirigida por el papa Inocencio VI al maestre del Hospital, Roger des Pins, en enero de 1359 nos proporciona algunos detalles suplementarios sobre lo que sucedió. Según el pontífice, Gutier Gómez de Toledo estaba acusado del asesinato de Lope Sánchez de Vendaña, comendador mayor de Segura y de Castilla de la Orden de Santiago. Al parecer, Pedro I obligó al comendador hospitalario de Reinoso, Sancho Ortiz de Salcedo, a hacer freire sanjuanista a Gutier Gómez. Después el monarca le introdujo en el priorato. Finalmente envió una carta al papa solicitando su ratificación y aprobación de la colación del priorato a Gutier Gómez de Toledo. Por medio de la violencia y del miedo también hizo que los hospitalarios castellanos mandatan otra carta a Inocencio VI suplicando lo mismo. Por supuesto, el papa techazaba este proceder, que iba en perjuicio de los derechos del prior legal, Juan Fernández de Heredia. Sospechando que igualmente el monarca castellano intentaría obtener la aprobación del maestre de la Orden, el pontífice prohibió a Roger des Pins que híciera caso a cualquier petición del rey o de los freires castellanos para ratificar la colación del priorato realizada de esta forma ${ }^{21}$.

El maestre respondió al escrito pontificio encargando a dos visitadores restablecer el orden y la disciplina en Castilla en junio de 1359. Sin embargo, en la práctica durante varios años se va a prolongar una situación anómala de coexistencia de dos priores, uno legal (Heredia) y otro de hecho, sostenido por Pedro I. Gutier Gómez de Toledo prolongará su mandato hasta 1363. Después será sustituido por Gómez Pérez de Porres como prior mayoritariamente reconocido dentro de Castilla entre 1364 y 1367 . En cambio, Juan Fernández de Heredia siguió siendo el prior castellano para el papa y para el resto de la Orden hasta 1369, cuando tuvo que abandonar el puesto por la prohibición establecida por un capítulo general de la Orden en 1367 de acumular más de un priorato ${ }^{22}$. En

18 LÓPEZ DE AYALA, Pero, Crónica del rey don Pedro y del rey don Enrique, su bermano, bijos del roy don Abfonso Onceno, vol. 1, Buenos Aires 1994, pág. 278.

19 DíAZ MARTín, Luis Vicente, «Los maestres de las órdenes militares en el reinado de Pedro I de Castillam, Hispania 145 (1980) 305 y 317.

20 Moxó, Salvador de, «El auge de la nobleza urbana de Castilla y su proyección en el ámbito administrativo y rumal a comienzos de la Baja Edad Media (1270-1370)m: Boletint de la Real Academia de la Historia 178 (1981) 477-478.

21 ZUNZUNEGUI ARAMBURU, José, Bulas y curtas secretas de Inocencio VI (1352-1362), Roma 1970, págs. 358-359.

22 DELAVILLE L.E ROUIX, Joseph, Les Hospitakiers à Rhodes jusqu'à la mort de Pbilibert de Naillac (1310-1421), París 1913, págs. 139 y 163.

Hipania, LVIII/2, núm. 199 (1998) 537-557 
1365 el pontífice Urbano V hubo de dirigirse a Pedro I y a Gómez Pérez de Porres para convocar a éste último a una asamblea de los hospitalarios en Carpentras, pero se limitó a nombratle como utegenti prioratum Castelle et Legionis» sin especificar su nombre ${ }^{23}$.

A pesar de todo, parece que al final de su mandato, entre los años 1368 y 1369, Juan Fernández de Heredia volvió a ejercer la administración efectiva del priorato de Castilla ${ }^{24}$. De esta forma, el segundo intento de la monarquía castellana por imponer a una persona de su agrado como prior del Hospital también se saldó con un fracaso.

\section{PUGNAS INTERNAS DE LOS HOSPITAYARIOS POR EL PRIORATO DE CASTIIA A FINES DEL SIGLO XIV Y COMIENZOS DEL XV}

Da la impresión de que, a continuación, la monarquía dejó momentáneamente de tratar de imponer a sus candidatos para el priorazgo de San Juan tras ver rechazadas sus dos tentativas al respecto. Por to menos, los siguientes enfrentamientos que conocemos por el puesto de prior de Castilla son protagonizados por los propios miembros de la Orden, aparentemente sin interferencias externas. Como vamos a tener ocasión de comprobar, prácticamente cada vez que el cargo quedaba vacante durante este periodo se desataban fuertes pugnas entre los hospitalarios castellanos por conseguir el puesto. Por regla general, los protagonistas de las disputas dan la impresión de ser siempre miembros de la Orden de cierta categoría. Suelen estar dotados por lo menos del cargo del comendador. Parecen proceder de linajes de la pequeña y mediana nobleza que tenían una estrecha vinculación con el Hospital.

El siguiente prior de Castilla documentado después de Heredia es Lope Sánchez de Somoza. Este personaje va a mantener un largo enfrentamiento con las autoridades superiores de la Orden que concluirá con su destitución. Los orígenes del problema se remontan a 1373, cuando el papa Gregorio XI impuso a los hospitalarios una talla o contribución especial de 20.000 flotines durante una asamblea de la Orden celebrada en Aviñón. La finalidad de este tributo era financiar una expedición contra los turcos ${ }^{25}$. Al parecer, el prior y los comendadores castellanos rechazaron pagar tanto su parte de este subsidio en el plazo previsto para ello como la «responsión» o impuesto anual debido al maestre y convento de Rodas. Entonces Gregotio XI encomendó el asunto al obispo de Oporto, Pedro, y al cardenal de San Vital, Guillermo. Ambos prelados excomulgaron al prior Lope. Por su parte Juan Fernández de Heredia, quien era entonces lugarteniente del Maestre en Occidente, suspendió a Lope

23 DeLaville LE RoulX, Joseph, «Bulle de convocation d'une assemblée des hospitaliers a Carpentras (1365)m: Mélanges sur l'Ordre di Saint Jean de Jérusalem, Paris 1910, XVI, págs. 3-4.

24 AHN, Códices, 603-B, págs. 35, 37, 43, 53.

25 LUT'TRELL, Anthony, "Gregory XI and the Turks: 1370-1378»: Latin Greece, the Hospitallers and the Crusades 1291-1440, Londres 1982, XV, 404-405. 
de su administración del priorato de Castilla. A pesar de estas medidas, no reconsideró su postura y el problema se prolongó. El obispo y el cardenal hicieron que su excomunión y suspensión de la administración del priorato fueran anunciadas públicamente por los arzobispos de Toledo, Compostela y Sevilla, así como por sus obispos sufragáneos. Por su parte Heredia, contando con la aprobación de otra asamblea de priores y comendadores del Hospital reunida en Aviñón en 1375, terminó por nombrar administrador del priorato de CastiLla y receptor de las rentas del mismo al comendador de Fresno el Viejo, Rodrigo Gómez. En diciembre de aquel mismo año el papa Gregorio XI escribió a todos los comendadores castellanos de la Orden, ordenándoles que en lo sucesivo obedecieran al citado Rodrigo Gómez y no a Lope ${ }^{26}$.

Sabemos que antes de ser prior, Lope Sánchez de Somoza había sido comendador de Cerecinos en 1357 y 1358, y que por la misma época había administrado varias encomiendas castellanas en nombre de Heredia cuando este era el prior ${ }^{27}$. Podría ser tentador considerarle como un hospitalario cuya carrera se hubiera desarrollado siempre en Castilla. En tal caso, quizás habría acaudillado un movimiento de resistencia de los hospitalarios castellanos frente a las exigencias de Rodas y del Papa. Sin embargo, carecemos de más documentación que avale tal hipótesis. Tan sólo conocemos que tras su destitución reaccionó acudiendo a Rodas. Una vez allí reconoció que debía la suma de 10.000 florines y se comprometió a pagarla en varios plazos. Parece que consiguió así que se le devolviera la administración del priorato. Sin embargo, al final no llegó a efectuar un primer pago de 3.500 florines en la fecha prevista para ello, la navidad de 1380. Las consecuencias fueron la renovación de su excomunión y su destitución en $1381{ }^{28}$.

En efecto, el 5 de julio de ese año Juan Fernández de Heredia, quien entretanto había llegado a ser maestre del Hospital, junto con el convento de Rodas nombró prior de Castilla y León por diez años a Pedro de Ibies. En el texto se señalaba que el priorato estaba vacante porque Lope Sánchez de Somoza había sido legítimamente privado y destituído de él. Según el contenido del documento de nombramiento, Pedro de Ibies era un miembro de la Orden que había residido en Rodas durante muchos años, por lo que su designación puede interpretarse como una victoria de las autoridades centrales de Rodas sobre los hospitalarios castellanos. Sin embargo, parece que el nuevo prior debió de encontrar resistencias o no estaba muy seguro de la legalidad de la concesión de su cargo, ya que posteriormente se preocupó por obtener nada menos que tres ratificaciones de su nombramiento. En 1382 el papa de Aviñón, Clemente VII, confirmó a Pedro de Ibies la concesión del priorato de Castilla por el maestre Heredia que acabamos de citar. Al año siguiente era el mismo Juan Fernández de Heredia, maestre del Hospital, quien con la autoridad del capitulo general de la Orden que se estaba celebrando entonces en Valence sur le Rhòne ratificó a Pedro Díez de Ibies como prior de Castilla y León por diez años. Finalmente

26 AHN, OOMM, carpeta 598, n. $^{\circ} 96$.

27 AHN, Códices, 602 B, folios 142v-143r, 143v, 144v-145r, 148r, 162v-163r, 165r.

28 DelaVille le RoulX, Joseph, Les Hospitaliers à Rhodes, París 1913, págs. 195-196.

Hipania, LVIII/2, núm. 199 (1998) 537-557 
en 1384 de nuevo Clemente VII confirmó a Pedro de Ibies la concesión del priorato y las dos ratificaciones posteriores. Además, revocó cualesquier otras concesiones del priorato que pudieran haber sido hechas por el papa o con su autoridad a otras personas. ${ }^{29}$

Apenas resuelto este conflicto de la manera que hemos visto, con una completa victoria de las instancias supetiores de la Orden sobre los hospitalarios castellanos, se empezaron a poner las bases de otro que va a durar hasta comienzos del siglo XV. Sabemos que Pedro de Ibies o Pero Díaz de Iveas siguió siendo prior de San Juan hasta su muerte, ocurrida en 1385 cuando combatía a favor del rey Juan I de Castilla en la batalla de Aljubarrota ${ }^{30}$. Durante un año se hizo cargo del priorato Rodrigo Gómez de Cervantes, lugarteniente de prior, quien era el comendador de Fresno el Viejo que hemos visto ser nombrado provisionalmente administrador del priorato en 1375. Sin embargo, el priorato castellano va a sufrir ahora los efectos de la política general de descarado favoritismo hacia sus parientes practicada por el maestre Juan Fernández de Heredia. En 1386 el citado maestre nombró prior de Castilla a un familiar suyo, Sancho Martínez de Heredia, quien era por consiguiente miembro de un linaje nobiliario aragonés. Este personaje había sido comendador de Quiroga hasta 1381 y después comendador de Cerecinos y de Benavente. Sin embargo, Sancho Martínez de $\mathrm{He}$ redia no llegó a disfrutar del cargo de prior durante muchos años. En 1394 perdió el puesto a pesar de su parentesco con el maestre de la Orden ${ }^{31}$.

Los motivos de su destitución son bastante oscuros. Sólo sabemos que fue privado de su cargo por el papa de Aviñón, Clemente VII, al haber perpetrado perjurio y otras faltas despreciando los mandatos del pontífice. Como la vacante se había producido en Aviñón, de forma excepcional la provisión del priorato correspondía al papa. El pontífice confirió el puesto a Rodrigo Gómez de Cervantes el 29 de mayo de 1394. Ese mismo día Clemente VII ordenó al obispo de Calahorra, al deán de la Catedral de Salamanca y al prepósito de la iglesia de San Desiderio de Aviñón que pusieran en posesión del priorato del Hospital en Castilla y León a Rodrigo Gómez de Cervantes o a su procurador. En efecto, al final fue el prepósito de San Desiderio, Hugo, quien ejecutó la decisión pontificia el 13 de julio de $1394{ }^{32}$.

Sin embargo, parece que Sancho Martínez de Heredia no admitió su destitución y el conflicto entre ambos priores se prolongó hasta comienzos del siglo XV. En el archivo sanjuanista de Consuegra se conservaba bastante documentación sobre este pleito, que desgraciadamente no ha llegado hasta nosotros ${ }^{33}$. La disputa terminó el 21 de diciembre de 1405 cuando ambas partes llegaron a

29 AHN, OOMM, carpeta 570, n.. 12 .

30 LÓPEZ DE AYALA, Pedro, «Crónica de Juan Ex: Crónicas de los rejes de Castilla, vol. 2, Madrid 1953, pág 105.

31 DELAVLle LE RoulX, Joseph, Las Hospitaliers à Rhodes, Paris 1913, págs. 239-242.

32 AGP, Infante don Gabriel, Secretaria, legajo 760.

33 GuERRERO VENTAS, Pedro, El arcbito prioral-sanjuanista de Consuegra. Resumen de sus fondos documentales, Toledo 1985, págs. 91, 92, 99, 103. 
un acuerdo en Castronuño. El prior de la iglesia de Rodas, Gautier Craxi, lugarteniente del maestre y del convento de Rodas, aseguró a Sancho Martínez de Heredia, quien era entonces comendador de Cerecinos, la posesión vitalicia de su encomienda. A cambio, Sancho Martínez de Heredia renunció a todos los derechos que pudiera tener al priorato de Castilla y León, y a otras encomiendas de la Orden en presencia del prior, Ruy Gómez de Cervantes ${ }^{34}$.

Sin más problemas, Ruy Gómez de Cervantes siguió siendo prior hasta su muerte en 1416. Entonces se produjo un nuevo conflicto al disputarse el cargo tres miembros de la Orden. Todos ellos eran comendadores castellanos del Hospital y al menos dos ellos pertenecían a linajes nobjliarios con estrecha vinculación a la Orden. Uno de ellos, Diego Gómez de Cervantes, era comendador de Fregenal de la Sierra y pariente del prior fallecido. Otro, Alfonso Martínez de Heredia, comendador de Wamba, era familiar del antiguo maestre Juan Fernández de Heredia. Finalmente el tercero, Fernando de Cardeñas, era comendador de Paradinas de San Juan. En un principio el maestre, Filiberto de Naillac, nombró prior a Fernando de Catdeñas en noviembre de 1416. Sin embargo, éste terminó siendo recusado por lo que el maestre tuvo que conferir el priorato a Diego Gómez de Cervantes en 1417. Para apaciguar los ánimos, concedió a los otros candidatos dos encomiendas: la de Portomarín a Fernando de Cardeñas y la de Población de Campos a Alfonso Martínez de Heredia. Cardeñas se contentó con esta solución, pero Alfonso Martínez no. En 1418 apeló a una asamblea de los hospitalarios que Filiberto de Naillac había reunido en Aviñón. Tras estudiar el problema, la asamblea se inclinó por la decisión tomada por el maestre. Alfonso Martínez de Heredia no acató la medida, por lo que el capítulo general de la Orden celebrado en Rodas en 1420 le suspendió en sus funciones ${ }^{35}$.

\section{LA MONARQUÚA IMPONE A SUS FAVORITOS EN EL PRIORATO DEL HOSPITAL (MEDIADOS DEL SIGLO XV)}

A partir del reinado de Juan II la monarquía vuelve a presionar para colocar a sus candidatos en el priorazgo de San Juan. A diferencia de lo que había ocurrido en el siglo anterior, esta vez sus esfuerzos se verán coronados con el éxito. Por lo menos en dos ocasiones las personas que acceden al cargo de prior se caracterizan no por su alta extracción social, sino por gozar del favor real en determinadas circunstancias.

La monarquía castellana va a obtener varias concesiones pontificias tras el fin del Cisma de Occidente que permitirán al tey tener derechos en la designación de cargos de la Iglesia y de las órdenes militares. La Orden del Hospital también se verá afectada en este proceso. En realidad, nuestro caso se halla inserto en un proceso más general de progresiva intervención de la monarquía en

34 AGP, Infante don Gabriel, Secretaria, legajo 586.

35 DELAVILLe l. ROULX, Joseph, Les Hospitaliers à Rbodes, París 1913, págs. 338-340.

Hipania, LVIII/2, núm 199 (1998) 537-557 
la asignación de beneficios eclesiásticos ${ }^{36}$. En primer lugar, sabemos que Juan II hizo una petición al papa Martín V al respecto. Según el monarca, los reyes de Castilla acostumbraban intervenir en la provisión de las vacantes en los maestrazgos de Santiago, Calatrava y Alcántara, en el priorato castellano de la Orden de San Juan y en las iglesias catedrales. Más concretamente, por lo que se refiere a nuestro caso, Juan II alegaba que cuando quedaban vacantes los maestrazgos de las órdenes militares y el priorato hospitalario de Castilla, los monarcas castellanos tenían la antigua costumbre de proveerlos en personas idóneas. Sin embargo, esto fue derogado durante su minoría de edad, cuando el reino reconocía al papa de Aviñón, Pedro de Luna, también conocido como Benedicto XIII. En consecuencia Juan II solicitó a Martín V que mandara que se guardara aquella costumbre. En efecto, en octubre de 1421 el papa resolvió que se respetaran los antiguos derechos y costumbres del rey de Castilla al hacer las provisiones de las iglesias catedrales, maestrazgos y priorato ${ }^{37}$. Juan II encontró que el contenido de esta bula era demasiado sumario y recogía muy imperfectamente sus peticiones, por lo que solicitó al pontífice otro documento cuya redacción respondiera mejor a los deseos reales. En efecto, en diciembre de 1421 Martín V dirigió al monarca castellano un extenso texto en el que reconocía plenamente el patronato real sobre la iglesia castellana y las ótdenes militates, incluyendo explicitamente entre ellas al priorato del Hospital. El papa anulaba cualquier novedad que hubiera hecho al respecto Benedicto XIII. Más concretamente, el pontífice parece reconocer al rey de Castilla el derecho de presentación en las vacantes y la necesidad de su aprobación por escrito para tomar posesión de los cargos. Todo ello se presentaba como una restauración de unos derechos concedidos con anterioridad por los pontífices a los monarcas castellanos por su labor en pro de la extensión de la religión cristiana a costa del Islam ${ }^{38}$.

Como hemos tenido ocasión de comprobar, en el caso de la Orden del Hospital no encontramos documentado este patronato regio hasta entonces. En cambio, sí sabemos que Benedicto XIII se había arrogado el derecho de proveer directamente encomiendas y prioratos sanjuanistas no sólo en la Península Ibérica, sino también en Francia, a expensas de los derechos del maestre y del convento de Rodas ${ }^{39}$.

En cualquier caso, el hecho es que la monarquía castellana había logrado así legitimar y fundamentar jurídicamente sus intervenciones en la designación del prior del Hospital en su reino. No creemos que sea una casualidad el hecho de que pocos años después de la emisión de estas bulas encontremos testimoniado el primer caso en mucho tiempo de un prior designado para el cargo a ins-

36 NiETO SORIA, José Manuel, Iglesia y génesis del Estado moderno en Castilla (1369.1480), Madrid 1993, págs. 343-380.

37 GUTIÉRREZ, Constancio, «La política religiosa de los Reyes Católicos en España hasta la conquista de Granadas: Miscelanea Comillas 18 (1952) 255-256, documento 1.

38 AGP, Infante don Gabriel, Secretaria, legajo 760, 1421. Bulas de Martino V.

39 DELAVILle LE RoulX, Joseph, Les Hospitaliers à Rhodes, Paris 1913, pág. 323. 
tancias del rey ${ }^{40}$. Sabemos que en 1428 Juan II hizo prior de San Juan a don Rodrigo de Luna. Se trataba del tío del valido del monarca, don Alvaro de Luna. Don Rodrigo recibió esta dignidad gracias a la influencia de Alvaro de Luna sobre el rey. Esta última circunstancia es confirmada por varias fuentes ${ }^{41}$. Hasta entonces, Rodrigo de Luna había sido comendador hospitalario de Monzón, en Aragón. Curiosamente siguió conservando esta encomienda después de haberse convertido en prior de Castilla ${ }^{42}$.

También en la época de Alvaro de Luna la monarquía obtuvo otro logro importante para controlar el priorato del Hospital. En 1440 el papa Eugenio IV concedió al rey Juan II que el siguiente prior fuera nombrado directamente por el pontífice a propuesta del monarca ${ }^{43}$.

En este contexto no resulta sorprendente el conflicto suscitado por el priorazgo en 1456. Al parecer tras la muerte del prior Gonzalo de Quiroga, obtuvo el cargo legalmente Juan de Somoza. Este presentó la provisión al rey Enrique IV para obtener su aprobación. El monarca se opuso y presionó a Juan de Somoza para que renunciase en favor de su entonces favorito, Juan de Valenzuela. Somoza intentó resistir, pero al final hubo de ceder y Valenzuela se convirtió en prior de San Juan ${ }^{44}$.

Al igual que Juan II, Enrique IV también obtuvo del Papa alguna concesión para controlar la designación de los priores. En 1459 Pío II manifestó al monarca que procuraría proveer el priorato de San Juan en la persona idónea según el deseo del monarca. La concesión se encontraba inserta en otra más general que abarcaba también a los arzobispados, obispados y maestrazgos de las órdenes de Santiago, Calatrava y Alcántara ${ }^{45}$.

\section{UN LINAJE DE LA ALTA NOBLEZA OCUPA EL PRIORATO (FINES DEL SIGLO XV)}

Hasta este momento no hemos encontrado a miembros de linajes de la alta nobleza entre los priores del Hospital. En general, da la impresión que el cargo era ocupado por personas pertenecientes a la atistocracia baja o media. Incluso

\footnotetext{
40 Mata Carriazo, Juan de (ed.), Crónica de don Aluaro de Luna, Madtid 1940, pág. 70.

41 Carrillo de Huete, Pedro, Crónica del Halconero de Juan II, Madrid 1946, pág. 177. Barrientos, Lope, Refundición de la Crónica del Halconero, Madrid 1946, pág. 167.

42 Castrllín CorTada, Francisco, «Los sanjuanistas de Monzón (Huesca) (13191351)»: Cuadernos de Historia «Jerónimo Zurita» 47-48 (1983) 259.

43 SuÁreZ FernándeZ, Luis, CANEllas LóPlZ, Angel y VICENS VIVES, Jaime, Los Trastámaras-de Castilla y Aragón en el sigho XV, Madrid 1964: Historia de España, fundada por R. Menéndez Pidal, vol, 15, pág. 103. NIETO SORIA, José Manuel, Iglesia y génesis del Estado Moderno en Castilla (1369-1480), Madrid 1993, pág. 50.

44 PALENCIA, Alonso de, Crónica de Enrique IV, vol. 1, Madrid 1973, págs. 91-92. SÁNCHEZ-PARRA, María Pilar, Crónica anónima de Enrique IV de Castilla 1454-1474 (Crónica castellana), vol. 2, Madrid 1991, págs. 61-62.

45 AGP, Infante don Gabriel, Anexo, legajo 1, D.

Higpania, LVIl]/2, núm. 199 (1998) 537-557
} 
encontramos los casos de Rodrigo de Luna y de Juan de Valenzuela, que se distinguían no tanto por su alta extracción social sino por ser uno pariente del valido del monarca y el otro por ser favorito él mismo del rey. Esta situación va a cambiar de forma radical a fines del siglo XV. Entonces miembros de linajes de la alta nobleza alcanzan el priorato, a menudo de forma bastante violenta. Se trata, en concreto, de componentes secundarios de las importantes familias de los Estúniga y de los Álvarez de Toledo.

En primer lugar va a ser un miembro del linaje de los Estúñiga quien pretenda y finalmente consiga el priorato. Como es conocido, la de los Estúñiga o Zúñiga fue una de las más destacadas familias de la llamada "nobleza nueva" que se impone en Castilla durante los siglos XIV y XV ${ }^{46}$. La oportunidad para el cambio va a presentarse con la rebelión de la mayor parte de la aristocracia castellana contra el rey Enrique IV a partir de 1465 . El prior del Hospital, Juan de Valenzuela, se mantuvo fiel al monarca y luchó contra la sublevación. El maestre de Calatrava, Pedro Girón, derrotó entonces militarmente a Valenzuela y ocupó las más importantes fortalezas del priorato. A continuación, Pedro Girón entregó el priorazgo a Alvato de Estúniga, tercer hijo del conde de Plasencia ${ }^{47}$.

La facción nobiliaria opuesta a Enrique IV debió de aprovechar ha oportanidad para desplazar del cargo a Valenzuela y sustituirlo por Alvaro de Estúñiga. Las circunstancias concretas de la destitución de Valenzuela no son claras, pero parece claro que, políticamente anulado como estaba, no pudo oponer mucha resistencia. Además, la propia dinámica interna del conjunto de la Orden también jugó un papel en el caso.

Según Giacomo Bosio, cronista oficial de la Orden, el cambio se produjo de la siguiente manera: un capítulo genetal del Hospital celebrado en Roma en 1466 había impuesto una contribución extraordinaria para pagar deudas y sostener el convento de Rodas, consistente en la mitad de las rentas producidas por los bienes de la Orden en Occidente durante cinco años. El Papa Pablo II ratificó la medida. Entonces el maestre y el consejo del Hospital enviaron a Aries González del Río, canciller de la Orden y comendador de Wamba, y a Guido de Monte Arnaldo, comendador de la Caballería en el priorato de Toulousse, como embajadores y visitadores generales a España para recaudar este impuesto. Guido solicitó a Valenzuela que pagase todos los tributos del priorato que debía al tesoro común de la Orden y que no pagaba desde hacía varios años. Al no tener éxito procedió contra él y lo privó del priorato y del hábito sanjuanista. A continuación confirió el puesto a Alvaro de Estúniga, quien pagó rápidamente todas las sumas que Valenzuela debía al tesoro común de la Orden por

46 VILlALOBOS Y MARTINEZ-PONTRÉMULI, Maria Luisa de, «Los Estúñiga. La penetración en Castilla de un linaje de la nobleza nuevay: Cuadernos de Historia. Anexos de la revista Hispania 6 (1975) 327-355.

47 TORRES FONTES, Juan, Estudio sobre la Crónica de Enrique IV del Dr. Galínder de Carvajal, Murcia 1946, págs. 243, 245, 275-276. ENRÍQUEZ DEL CASIILLO, Diego, Crónica de Enrique IV, Valladolid 1994, págs. 240-241. 
cuenta del priorato. Sin embargo, Valenzuela apeló la causa a Rodas con la ayuda del canciller Aries del Río. Allí el maestre del Hospital, Battista Orsini, confirmó la destitución de Valenzuela y el nombramiento de Álvaro de Estúniga en 1472. Valenzuela sólo consiguió que el maestre lo absolviese de la privación del hábito y que obligara al nuevo prior a pagarle una pensión anual ${ }^{48}$.

Por su parte, las fuentes narrativas castellanas se limitan a telatar que en 1470 se presentó en Castilla un caballero de la Orden de San Juan y embajador del Maestre de Rodas, Guido de Monte Arnaldo, provisto de poderes del Maestre y de cartas del Papa Pablo II para proveer a Alvato de Estúñiga con el priorazgo de San Juan. Este logró tomar el castillo de Consuegra y se fortificó en él. Curiosamente su padre, el conde de Plasencia y duque de Arévalo, no le ayudó porque el maestre de. Santiago, Juan Pacheco, apoyaba entonces a Valenzuela. En cambio se alinearon a favor de Alvaro de Estúñiga los príncipes Fernando e Isabel, el arzobispo de Toledo y el linaje nobiliario de los Manrique. El conflicto se resolvió finalmente mediante la lucha armada. Saliendo de Alcázar de San Juan, Jorge Mantique derrotó en diciembre de 1470 a los partidarios de Valenzuela y del rey Enrique IV que habían partido de Ajofrín ${ }^{49}$.

La sustitución violenta de Valenzuela por Alvaro de Estúñiga en el priorato de San Juan puede interpretarse, a la luz de estos datos, como el resultado de una confluencia de intereses. Por una parte, los de las autoridades superiores de la Orden en Rodas, a quienes Valenzuela no pudo pagar sus contribuciones probablemente por el estallido de una guerra civil en Castilla. Sabemos que Valenzuela tomó partido en el conflicto a favor de Enrique IV y que a causa de ello perdió la mayor parte de los señoríos ligados al priorato. Este último factor debió agravar su incapacidad para hacer frente a las exigencias tributarias de Rodas. Los representantes de la Orden no debieron poner entonces ningún inconveniente a su sustitución por una persona que pagase todas las sumas atrasadas. Alvaro de Estúñiga debía contar con la capacidad financiera adecuada para hacer frente a estas deudas. Sabemos que su linaje disfrutaba de numerosas rentas ${ }^{50}$.

Por otra parte, también influyeron claramente los intereses de la facción nobiliatia entonces triunfante en Castilla, opuesta a Enrique IV y partidaria de los posteriormente conocidos como Reyes Católicos. La sustitución de un prior por otro debió insertarse dentro de la pugna existente entre partidos nobiliatios por colocar a sus partidarios en puestos dotados de cierto poder.

De todas formas, Valenzuela no renunció a sus derechos y siguió la lucha por la vía judicial. Parece que recurrió al Papa. Le fue desfavorable una primera

48 Bosio, Giacomo, Dell'Istoria della sacra religione et illustrissima militia di San Giovanni Gierosolimitano, vol. 2, Roma 1629, págs. 307-308, 333.

49 Valera, Diego de, Memorial de diversas hazañas. Crónica de Enrique IV, Madrid 1941, págs. 180-182. SANCHEZ-PARRA, María Pilar, Crónica anónima de Enrique IV de Castilla 14541474 (Crinica castellana), vol. 2, Madrid 1991, págs. 305, 320-321.

50 MARTÍNEZ MORO, Jesús, La renta feudal en la Castilla del siglo XV: los Stúnitga, Valladolid, Universidad de Valladolid, 1977,118 págs.

Hi.pania, LVIII/2, núm. 199 (1998) 537-557 
sentencia emitida por Antonio Vasch, canónigo de la Catedral de Segovia, subdelegado del obispo de Mondoñedo, quien fue el juez delegado para la causa por el Papa junto con otros colegas. Sin embargo, Valenzuela interpuso una apelación contra la sentencia. El juez delegado por la Sede Apostólica para resolverla fue el propio maestre del Hospital, Pedro d'Aubusson. Alvaro de Estúñiga envió un procurador, fray Antonio Farfán, a Rodas para seguir el pleito. En cambio, Juan de Valenzuela no acudió ni envió ningún representante. El resultado fue el que cabía esperar. En 1488 el maestre sentenció desde Rodas que Valenzuela había sido justamente privado de su cargo y que Alvaro de Estúñiga habia recibido el priorato de Castilla legalmente ${ }^{51}$.

\section{LA DISPUTA POR EL PRIORATO ENTRE DOS IMPORTANTES FAMILIAS DE LA ARISTOCRACIA CASTELIANA (COMIENZOS DEL SIGLO XVI)}

Tras su acceso al trono, los Reyes Católicos retomaron la política ya iniciada por Juan II y Enrique IV tendente a controlar la designación del prior de San Juan. Como hemos visto, cuando eran príncipes habían promovido el nombramiento de un partidario suyo, Alvaro de Estúñiga. Sin embargo, la manera como accedió éste al puesto indudablemente había supuesto un paso atrás para la monarquía como institución. Por tanto, no debe extrañarnos que rápidamente los Reyes Católicos pretendan devolver a la Corona el control en la designación del priot. En las instrucciones que dieron a sus embajadores ante el Papa en 1476,1479 y 1486 repetidamente se incluye al priorato de San Juan, junto a los maestrazgos de las otras órdenes militares, entre los cargos eclesiásticos que los diplomáticos debían solicitar al pontífice que proveyera sólo en los candidatos que los reyes le suplicasen ${ }^{52}$.

Como es conocido, pocos años más tarde se produjo la incorporación de los maestrazgos de las órdenes militares peninsulares a la Corona: el de Calatrava en 1489, el de Santiago en 1493 y el de Alcántara en 1494 53. Curiosamente, el priorato de San Juan en Castilla escapó a este proceso. Probablemente influyera el hecho de que se tratara de una orden internacional. Además, seguramente suponía un peligro potencial mucho menor para la monarquía. Por otra parte, el papel de los hospitalarios en el Mediterráneo Oriental frente a la creciente amenaza turca era bastante importante a fines del siglo XV ${ }^{54}$. En

51 AHN, OOMM, carpeta $573, \mathrm{n}^{\circ} 5$.

52 SUÁREZ FERNÁNDEZ, Luis, Politica internacional de Isabel la Católica. Estudio y documentos, vol. 1, Valladolid 1965, págs. 318, 426, y vol. 2, Valladolid 1966, págs. 340, 360.

53 JNVIERRE MUR, Aurea, «Fernando el Católico y las Ordenes Militates españolas»: Estudios del $V$ Congreso de Historia de la Corona de Aragón, vol. 1, Zaragoza 1955, págs. 287-300. SOLANO, Emma, La Orden de Calatraya en el siglo XV, Sevilla 1978, págs. 120-123. LADERO QUESADA, Manuel Fernando, «La incorporación del maestrazgo de Alcántara a la Corona»: Hispania $150(1982)$ 5-14.

54 VA'TIN, Nicolas, L'Ordre de Saint-Jean-de-Jérusalem, lEmpire ottoman et la Méditerranée orientale entre les deux sièges de Rhodes (1480-1522), París, Éditions Peeters, 1994, 571 págs. 
consecuencia, una hipotética incorporación de su priorato de Castilla a la Corona quizás hubiera acarreado cierto desprestigio para la monarquía hispánica.

Escogiendo una vía alternativa, los Reyes Católicos siguieron profundizando su política de estrecho control sobre el priorazgo durante los siguientes años. Es bastante significativo el hecho de que en 1504 la reina Isabel mandase a sus herederos en su testamento que no presentasen como candidatos para ocupar el priorato de San Juan, entre otros beneficios eclesiásticos, a personas que no fueran naturales de su reino ${ }^{55}$. En realidad este objetivo, aplicable a todos los cargos de la Iglesia castellana, era una vieja aspiración de la monarquía ${ }^{56}$. Posteriormente, sabemos que Fernando el Católico transmitió al papa Julio II, a través de su embajador Jerónimo de Vich, su interés porque el priorato del Hospital en Castilla fuera obtenido por una persona grata y fiel al rey. El pontífice accedió al deseo del monarca y en 1511 se reservó la provisión del priorato la próxima vez que quedara vacante, comprometiéndose a conferirlo a la persona idónea que el rey le escribiera ${ }^{57}$.

Dentro de esta estrategia, parece que desde comienzos del siglo XVI Fernando el Católico planeó un cambio en el linaje nobiliario que controlase el cargo, lo que desencadenó el último conflicto que vamos a estudiar en el presente trabajo. En 1501 suplicó al Papa que reservase la provisión del priorato de Castilla cuando quedase vacante para don Enrique de Toledo. Se trataba de un hermano del duque de Alba cuya carrera en la Orden de San Juan ya había sido apoyada por los Reyes Católicos antes. En 1496 habían escrito al maestre de la Orden recomendándole que concediera a don Enrique alguna encomienda. Más concretamente parece que era la encomienda de Chipre la que los monarcas deseaban para el hermano del duque de Alba, ya que simultáneamente solicitaron al dux de Venecia y al papa que hicieran cuanto estuviera en su mano para que don Enrique consiguiera dicha encomienda hospitalaria 58 . Sabemos que que la encomienda de Chipre era una de las más ricas de la Orden de San Juan ${ }^{59}$. Por lo tanto, esta petición de los Reyes Católicos parece delatar un inusitado interés por promocionat a Enrique de Toledo dentro de la Orden. Quizá ya en 1496 la monarquía estuviera preparando el terreno para la sustitución de los Estúñiga por los Álvarez de Toledo en el priorato de Castilla, intención que se pone claramente de manifiesto por primera vez en 1501, según acabamos de comprobar.

55 SANTA CruZ, Alonso de, Crónica de los Reyes Católicos, vol. 1, Sevilla 1951, pág, 329.

56 NiETo SORIA, José Manuel, Iglesia y génesis del Estado Moderno en Castilla (1369-1480), Madrid 1993, págs. 345-349.

57 AGP, Infante don Gabriel, Anexo, legajo 1, B.

58 TORRE, Antonio de la, Documentos sobre relaciones internacionales de los Reyes Católicos, vol. 5, Barcelona 1965 , págs. 244-245 y vol. 6, Batcelona 1966 , págs. 256-257.

59 LUTIRELL, Anthony, «The Hospitallers in Cyprus after 1291»: The Hospitallers in Cyprus, Rhodes, Greece and the West 1291-1440, Londres 1978, capitulo II, págs. 161-171. LUTTREL,, Anthony, "The Hospitallers in Cyprus, 1310-1378»: The Hospitallers of Rhodes and their Mediterranean Worla, Aldershot 1992, capitulo LX, págs. 155-184.

Hispania, LVIII/2, núm. 199 (1998) 537-557 
Sabemos que, en efecto, el papa Alejandro VI concedió la expectativa solicitada por los Reyes Católicos sobre el ptiorato de Castilla a Enrique de Toledo. Posteriormente, antes de ejecutar la bula pontificia, Fernando el Católico escribió al maestre de Rodas para obtener la misma concesión en 1504. En efecto, el maestre y su consejo decidieron complacer los deseos del monarca ${ }^{\omega}$.

Como es conocido, los Álvarez de Toledo constituían otro de los más importantes linajes nobiliarios de Castilla a fines de la Edad Media ${ }^{61}$. Tras la muerte de don Enrique de Toledo, al final va a ser un hijo del duque de Alba llamado Diego de Toledo el que aspire a ser prior del Hospital con el apoyo de Fernando el Católico. Según el cronista Alonso de Santa Cruz, después de la conquista de Navarra por el duque en 1512 Fernando obtuvo para su hijo del maestre de Rodas la reserva del priorato. Por su parte, los Estúñiga no se quedaron impasibles. Don Antonio de Estúñiga, hermano del duque de Béjar, conseguió a su vez del papa otra reserva del mismo priotato para él ${ }^{62}$.

Documentalmente sabemos que en 1512 el priorazgo había quedado vacante tras la muerte de Alvaro de Estúñiga. En marzo de dicho año Emerico de Amboise, maestre del Hospital, y el convento de Rodas nombraron procurador suyo en Castilla a Andrea de Amaral, comendador de la Vera Cruz en Portugal y canciller del convento de Rodas. Andrea debía comparecer ante Fernando el Católico como embajador de la Orden y buscar un varón noble e idóneo para concederle el priorato castellano. El candidato podía ser tanto un miembro de la Orden como un laico, para lo cual se le otorgaba la oportuna dispensa. Andrea habría de remover del priorato a cualquier otro posible ocupante ilegal. En efecto, este procurador y embajador hospitalatio finalmente designó prior de Castilla y León por diez años a Diego de Toledo en abril de 1513. En el texto de nombramiento, Andrea observaba que el puesto había quedado libre o por "resignación» o por muerte de Alvaro de Estúñiga ${ }^{63}$. Mientras, es interesante observar que, a diferencia de lo que había ocurtido en 1470, la cabeza del linaje de los Estúñiga había tomado decidamente partido por el candidato de su familia. En 1512 el duque de Béjar ya reconoció a su hermano como prior de San Juan ${ }^{64}$.

60 Bosio, Giacomo, Dell'Istoria della sacra religione et illustrissima militia di San Giovanni Gierosolimitano, vol. 2, Roma 1629, pág. 584.

61 Moxó, Salvador de, «El auge de la nobleza urbana de Castilla y su proyección en el ámbito administrativo y rural a comienzos e la Baja Edad Media (1270-1370)»: Boletín de la Real Academia de la Historia 178 (1981) 482-486. BINAYAN CARMONA, Narciso, «De la nobleza vieja...a la nobleza viejay: Estudios en bomenaje a Don Claudio Sáncbez Albornoz en sus 90 años, vol. 4, Buenos Aires 1986, págs. 122-123.

62 Santa Cruz, Alonso de, Crónica de los Reyes Católicos, vol. 2, Sevilla 1951, pág. 249.

63 AHN, OOMM, carpeta 573, n1 9.

64 TORRE, Antonio de la, y SUÁREZ FERNÁNDEZ, Luis, Documentos referentes a las relaciones con Portugal durante el reinado de los Reyes Católicos, vol. 3, Valladolid 1963, pág. 201. 
Quedaba asi planteado el conflicto entre las dos poderosas casas nobiliarias por este motivo, que ya fue estudiado en su momento por Guerrero Ventas ${ }^{65}$. Probablemente haya que poner en relación este repentino interés de las grandes familias de la nobleza castellana por el priorazgo de San Juan con la reciente incorporación a la Corona de los maestrazgos de las órdenes militares peninsulares. El priorato del Hospital quedaba así como el único cargo importante de las órdenes militares en Castilla que podía ser ocupado por algún miembro de la aristocracia. Antes probablemente tenía una importancia comparativamente menor y por consiguiente era ocupado por figuras de la baja $O$ mediana nobleza. En cambio, a partir de fines del siglo XV su importancia como plataforma de poder $y$ rentas de cierto valor para los segundones de la alta nobleza debió acrecentarse al cerrarse la vía de los maestrazgos. El resultado va a ser una seria disputa entre dos de los más destacados linajes de la aristocracia castellana en cuyo desarrollo la Corona va a desempeñar un papel decisivo.

Fernando el Católico reaccionó rápidamente contra los intentos de los Estúñiga para mantener a un miembro de su familia como prior del Hospital con el respaldo del papa. En 1514 el rey hizo varias gestiones diplomáticas en la corte pontificia para conseguir que León $\mathrm{X}$ retirase su apoyo a las pretensiones de los Estúniga. Conocemos las instrucciones que el monarca envió con este objetivo a uno de sus agentes en Roma, Fernán Pérez de Guzman, al menos en dos ocasiones. Ambas cartas son muy interesantes, ya que nos informan con más detalle sobre los pormenores del conflicto, si bien siempre desde el punto de vista interesado del rey. Sobre todo, constituyen un excelente testimonio sobre los derechos que la monarquía reivindicaba tener en la designación del prior de San Juan al final del periodo de nuestro estudio.

El primeto de estos escritos aparece fechado en Madrid el 18 de enero de 1514 616. En esta carta Fernando el Católico responde a otra previa de su enviado Fernán Pérez en la que exponía al monarca que León $\mathrm{X}$ pedía argumentos legales para anular la provisión del priorato obtenida por Antonio de Estúñiga del papa Julio II. Fernando reivindica que el priorato pertenecía al patronato real y que su provisión siempre se había realizado a súplica y voluntad del monarca castellano. Como ejemplo de ello ponía que el papa Alejandro VI había reservado el cargo a don Enrique de Toledo para cuando quedase vacante a súplica de la reina Isabel y de él mismo. La única excepción era la bula que Julio II había concedido sobre ello a don Antonio de Estúñiga, la cual en opinión del monarca no podía tener efecto porque violaba el patronato real, ya que se había otorgado sin la súplica previa del rey. Además, consideraba que el monarca tenía derecho a no admitir a la persona que hubiera recibido del papa la provisión de una dignidad importante para el reino y que no fuera fiel a la corona. Al contrario, debía suplicar al pontífice por otro que fuera fiel. Fernando el Católico

65 Guizraro VENTAS, Pedro, El gran priorato de San Juan en el Campo de La Mancha, Toledo 1969 , paigs. $190-195,354-355$.

66 AGP, Sección de Infante don Gabriel, Anexo, legajo 1, a.

Hilpania, J.V111/2, núm. 199 (1998) 537-557 
encargó a Fernán Pérez de Guzmán que expusiera todo esto a León X para que accediera a la solicitud real.

La segunda carta, fechada en el 30 de junio siguiente, es mucho más extensa y nos informa con más detalle del nacimiento del conflicto ${ }^{67}$. Según el rey, a súplica suya y de la reina recibió la provisión del priorato don Enrique de Toledo, hermano del duque de Alba. Sin embargo, posteriormente falleció y el monarca preparaba lo necesario para que el derecho al priorato pasara a don Diego de Toledo, hijo del duque, puesto que tenía que ser proveído a súplica del rey por corresponder a su patronato. Entonces don Antonio de Estúniga, sobrino del entonces prior don Alvaro de Estúniga, ocultamente consiguió que mediante el pago de una cantidad de dinero el papa Julio II le diera una bula de provisión del priorato por resignación de don Alvaro. Como todo se había realizado contra su patronato y Antonio de Estúniga era un aliado de Francia y no una persona fiel a la Corona, Fernando el Católico no dio lugar a que tuviera efecto la bula, sino que mandó secuestrar las villas, fortalezas y rentas del priorazgo. A continuación escribió al maestre de Rodas para denunciar lo ocurrido y le rogó que hiciera provisión del cargo en favor de Diego de Toledo. El maestre envió entonces una citación al prior Alvaro de Estúñiga para que acudiese a Rodas en cierto plazo. La citación fue presentada al prior y su respuesta fue remitida al maestre. Este terminó procesando judicialmente a Alvaro de Estúñiga y privándole del cargo de prior. A continuación el maestre concedió un poder al canciller de Rodas, enviado como embajador de la Orden al monarca, para que hiciera provisión del priorazgo a Diego de Toledo, como en efecto hizo. Fernando el Católico terminaba encargando a Fernán Pérez de Guzmán que suplicase en su nombre al papa León $\mathrm{X}$ que revocase la provisión del priorato otorgada por su antecesor Julio II y que confirmase el nombramiento de prior que la propia Orden había hecho a Diego de Toledo. El rey recomendaba a Fernán Pérez que para conseguir todo aquello utilizase la ayuda del cardenal de Sorrento, del cardenal de Aragón, sobrino del monarca, y del propio embajador de Fernando el Católico en Roma, Jerónimo de Vich.

Sin embargo, conocemos que el conflicto se prolongó bastantes años e incluso estuvo a punto de provocar un choque violento. Tras la muerte del rey Fernando, Antonio de Estúñiga obtuvo medidas a su favor del nuevo monarca, Carlos I, en Flandes y del papa en Roma. Los Estúñiga y los Álvarez de Toledo estuvieron entonces al borde de un enfrentamiento armado. El cardenal Cisneros, regente del reino, resolvió la situación haciendo secuestrar el priorato y expulsando de él a Diego de Toledo en $1517^{68}$.

Finalmènte, el conflicto se tesolvió a través de una sentencia arbitral pronunciada por Carlos I. Tanto Diego de Toledo como Antonio de Estúñiga tendrían el título de prior de Castilla y León. La jurisdicción del priorato se dividió entre ambos. A Antonio de Estúñiga le correspondieron las 18 encomiendas

67 AGP, Infante don Gabriel, Anexo, legajo 1, a.

68 SaLudador Merino, Francisco, «La Casa de Alba en el Priorato de San Juann: Noria. Cuadernos de temas alcazareños 1 (1962) 17-32. 
existentes en los teinos de Toledo, Murcia y Galicia, y en las diócesis de Sevilla, León, Sigüenza y Ciudad Rodrigo. Por su parte, a Diego de Toledo le tocaron las 15 encomiendas situadas en las diócesis de Zamora, Salamanca, Plasencia y Burgos, y en la "provincia» de Campos ('Tierra de Campos?). En caso de que el valor anual de las rentas de la parte asignada a Diego no llegase a los 2.000 ducados, Antonio de Estúniga habría de suplir la cantidad que faltase con las rentas de su porción del priorato. En 1519 el papa León X confirmó esta sentencia y absolvió a ambos contendientes de las penas y censuras eclesiásticas en que pudieran haber incurrido a lo largo de todo el proceso ${ }^{69}$.

Según parece, el reparto también afectó al principal señorio ligado al priorato, el Campo de San Juan en La Mancha. A Antonio de Estúñiga le correspondieron las villas de Consuegra, Madridejos, Camuñas, Urda, Turleque, Tembleque, Villacañas, Villarta de San Juan, Herencia y Arenas de San Juan. En cambio, las de Alcázar de San Juan, Argamasilla de Alba, Quero y Villafranca de los Caballeros tocaron a Diego de Toledo. La división del priorato fue sancionada por el Maestre de la Orden en 1531 y duró bastante tiempo. No se decidió su reunificación hasta $1566^{70}$.

\section{CONCLUSION}

El resultado final del conflicto favoreció indudablemente a la Corona, que fue quien lo resolvió aparentemente sin la intervención decisiva de ninguna otra instancia. En efecto, durante la Edad Moderna la monarquia controló en la práctica la designación de los priores de Castilla, que fueron por lo general personas cercanas al rey o parientes suyos. El proceso se completó en el siglo XVIII, cuando el priorato quedó vinculado hereditariamente a uno de los hijos de Carlos III, el infante don Gabriel, y a sus descendientes ${ }^{71}$. Parece que no hubo necesidad de una incorporación formal del priorazgo a la Corona. La monarquía pudo comprobar la utilidad de la existencia autónoma de esta figura cuando el prior Antonio de Zúñiga o Estúñiga intervino eficazmente en la represión de la sublevación de Toledo durante el movimiento de las Comunidades, en un momento de aguda crisis del poder real ${ }^{72}$. Por otra parte, tras el traslado de su sede central de Rodas a Malta, la Orden en su conjunto se convirtió en una estrecha aliada de la Corona española en su política mediterránea frente a las potencias islámicas durante la Edad Moderna ${ }^{73}$. En estas circuns-

\footnotetext{
69 SAHN, OOMM, carpeta $572, \mathrm{n} 147$.

70 AGUIRRE, Domingo, El gran priorato de San Juan de Jerusalen en Conswegra, en 1769, Toledo 1973 , págs. $149,153-154$.

71 Guerrero VenTAs, Pedro, El gran priorato de San Juan en el Campo de La Mancha, Toledo 1969 , págs. 303-309.

72 PÉREZ, Joseph, La revolución de las Comunidades de Castilla (1520-1521), Madrid 1979, 3.0 ed., págs. 331-350, 360-379.

${ }_{73}$ SAJVA, Jaime, La Orden de Malta y las acciones navales españolas contra turcos y berberiscos en los siglos XVIy XVII, Madrid, Instituto Histórico de Marina, 1944, 447 págs.

Hi.pania, LVIII/2, núrn. 199 (1998) 537-557
} 
tancias, no debe sorprendernos que la incorporación a la Corona y la asunción por el monarca español del maestrazgo de la Orden en sus dominios sólo se produjese en una fecha tan tardía como 1802, tras la crisis desatada con la ocupación de Malta por Napoleón en $1798^{74}$.

En definitiva, al igual que las órdenes militares peninsulares, los hospitalarios castellanos también tuvieron frecuentes disputas por la cabeza de su Orden en Castilla durante la Baja Edad Media. El hecho de formar parte de una organización internacional introduce un primer factor de diferenciación en estos conflictos, al desempeñar en ellos un papel los intereses del maestre y del convento central de la Orden establecido en Rodas. La monarquía castellana es otro de los principales protagonistas en liza, pero sus frecuentes intervenciones sólo parecen tener un éxito pleno a partir del siglo XV. Paralelamente, se observa una interesante evolución en el origen social de los aspirantes al priorato del Hospital, que pasan de ser miembros de la pequeña o mediana nobleza a segundones de los principales linajes de la alta aristocracia castellana.

74 García MARTin, Pedro, «La incorporación a la Corona del patrimonio hispano de la Orden de Maltay: Antiguo Régimen y liberalismo. Homenaje a Miguel Antola, vol. 2, Madrid 1995, págs. 169-184.

Hispantia, LVIII/2, núm. 199 (1998) 537-557 